\title{
Self-regulated Mobile Learning and Assessment: An Evaluation of Assessment Interfaces
}

\author{
Melisa Koorsse, Department of Computing Sciences, \\ Werner Olivier, The Govan Mbeki Mathematics Development Unit, \\ and Jean Greyling, Department of Computing Sciences, \\ Nelson Mandela Metropolitan University, \\ Port Elizabeth, South Africa
}

\section{Melisa.Koorsse@nmmu.ac.za waolivier@nmmu.ac.za Jean.Greyling@nmmu.ac.za}

\begin{abstract}
Assessment for learning has an important role to play in self-regulated learning but the assessment interface can impact learner motivation and performance. Learners are able to assess their knowledge of learning content and, through repeated assessment and high-quality feedback, close the gap between their current performance and the performance goals of the assessment. Technology, specifically, mobile devices, provide learners with access to these assessments regardless of time or location. The widespread use and acceptance of mobile devices allow users in remote areas, where there is a lack of infrastructure and suitably qualified teachers, access to learning material and content. The challenge is to ensure the assessments are presented in such a way so that self-regulated learning is supported. In this study, two different multiple-choice assessment interfaces are presented to support the learning of secondary school mathematics and science content in South Africa using a Mxit application called MathWars. The two assessments methods were evaluated to determine how self-regulated learning principles are supported. The results of the study identify key findings with regards to learner motivation to retake assessments and the importance of identifying performance goals and access to solutions.
\end{abstract}

Keywords: Self-regulated mobile learning, mobile assessment, m-learning, mobile learning management system, multiple-choice assessment.

\section{Introduction}

In developing countries, particularly sub-Saharan Africa including South Africa, access to resources, such as textbooks and computers, and socio-economic status are key contributing factors

Material published as part of this publication, either on-line or in print, is copyrighted by the Informing Science Institute. Permission to make digital or paper copy of part or all of these works for personal or classroom use is granted without fee provided that the copies are not made or distributed for profit or commercial advantage AND that copies 1) bear this notice in full and 2) give the full citation on the first page. It is permissible to abstract these works so long as credit is given. To copy in all other cases or to republish or to post on a server or to redistribute to lists requires specific permission and payment of a fee. Contact Publisher@InformingScience.org to request redistribution permission. to learning in certain areas (Keble, 2012). The trend is to install cell phone networks in rural areas (Sharples, Taylor, \& Vavoula, 2005), allowing people in rural communities to make phone calls as well as access mobile services such as text and multimedia messaging and even data services. Mobile-learning (M-learning) is a medium that, if used appropriately, can provide learning support to learners in all areas and envi- 
ronments, but specifically rural and disadvantaged areas where there is inadequate access to learning resources (Greyling, Koorsse, Ngundu, \& Kyazze, 2013).

A problem when developing a system to support learning using mobile devices is that not much emphasis in related work is placed on the impact of the assessment interface on the learning process. The assessment interface is the gateway for the user to the learning content. There are different ways in which questions and the solutions can be presented during and after the assessment. This research explores the two different formative assessment interfaces implemented in the development of a mobile learning and assessment application called MathWars, which was developed to address the need of the Govan Mbeki Mathematics Development Unit (GMMDU) to support the teaching and learning of mathematics and science amongst secondary school teachers and learners, respectively. The assessment interfaces were implemented as part of a text-based mobile learning application for mathematics and science to support secondary school learners in South Africa.

The research goal of this study is to evaluate how the two formative assessment interface methods implemented support self-regulated learning by comparing them in terms of user performance and motivation to use the assessment resources provided. The findings provide insight and recommendations as to how questions and solutions should be presented to users. In order to effectively evaluate the two assessment interfaces, an understanding of the purpose of assessment and principles that should be employed to promote self-regulated mobile learning is necessary, together with an understanding of the purpose and goals of the mobile application MathWars.

\section{M-Learning and Assessment}

Studies have demonstrated the effectiveness of online learning, including assessment and feedback (Hwang \& Chang, 2011), which has become part of the educational strategy in higher education (Gikandi, Morrow \& Davis, 2011; Snell \& Snell-Siddle, 2013) and school environments (F. Martin \& Ertzberger, 2013; Sheppard, 2011; Tan \& Liu, 2004). Learners prefer to learn at their own pace and complete assignments in their own time (F. Martin \& Ertzberger, 2013; Tallent-Runnels et al., 2006). Online environments are as effective as traditional classroom environments; however, the quality of online instruction provided to learners affects the effectiveness of the learning. Teaching and learning activities need to be well planned and technology should promote, not impede, the learning process (Snell \& Snell-Siddle, 2013; Tallent-Runnels et al., 2006).

M-learning is an approach to electronic learning (E-learning) that utilises mobile devices (Andronico et al., 2003; Riad \& El-Ghareeb, 2008). M-learning allows learning to take place in different contexts that suit the learner (Chu, Hwang, \& Tsai, 2010; Motiwalla, 2007; Quinn, 2001; Sharples, Taylor \& Vavoula, 2005). Studies have shown that while learning takes place in traditional learning environments such as at home, work or school, learning can also occur outdoors, in a friend's house, places of leisure, or other places such as cafes, cars or a doctor's surgery (Sharples et al., 2005; Vavoula, 2005; Virviou \& Alepis, 2005). The mobility of m-learning devices is the key motivator for use, with the most motivating learning tasks being access to information, authoring, and communication (R. Martin, MacGill, \& Sudweeks, 2013). Learning within different contexts and locations requires the support of appropriate technology (F.Martin \& Ertzberger, 2013). Mobile learning requires a laptop, tablet, or mobile phone that will allow learners to access learning content. A wide variety of devices currently exist and are being developed, all with different limitations and advancements that developers of mobile learning systems can leverage (Andronico et al., 2003).

There has been an increase in the use of technology in formative assessment and self-regulated learning (Hwang \& Chang, 2011; Sheppard, 2011). Formative assessment refers to assessment 
that is intended to provide feedback on performance and accelerate learning (Sadler, 1998). Selfregulated learning refers to the degree to which learners can regulate aspects of their motivation, thinking, and behaviour during learning, resulting in active monitoring and regulation of learning processes (Pintrich \& Zusho, 2007). The processes can include setting of learning goals, the development of strategies to achieve goals, management of resources, and how to positively respond to assessment and learning feedback.

Educational assessment can benefit from the use of technology (Riad \& El-Ghareeb, 2008; Scalise \& Gifford, 2006). E-learning systems can expand testing possibilities beyond the limitations of paper-based tests (Olufisoye \& Ola, 2013; Scalise \& Gifford, 2006). The computer-based testing platform can offer high-quality formative assessment that supports classroom activities and goals. Technology is able to provide innovative assessment, scoring, reporting, and real-time feedback for teachers and learners (Olufisoye \& Ola, 2013). Before developing an effective assessment system, it is important to understand the purpose and benefits of assessment in general, and specifically the multiple-choice assessment format, including advantages, limitations, and learning principles that can be applied to promote self-regulated learning.

\section{Purpose and Benefits of Assessment}

Assessment is an important part of learning success and can be used to direct and even modify the teaching approach (Riad \& El-Ghareeb, 2008). It is a formal process that is used to gain information about a learner's educational status in terms of knowledge, attitude, and skills. Assessment can also be used to encourage and support learning as well as increase learners' confidence. Repeated continuous assessment can be used to highlight a learner's weaknesses and strengths, thus helping them to increase their self-confidence (Riad \& El-Ghareeb, 2008). Three different assessment approaches or purposes are identified (Bell \& Cowie, 2001; Earl, 2003):

1. Assessment of Learning: This is the predominant form of assessment and can also be referred to as summative assessment. The purpose is to certify learning and report on a learner's progress. This assessment is used to monitor educational progress or improvement compared to standards of performance. The feedback or results from summative assessment is significant for reporting to policymakers, parents and the public.

2. Assessment for Learning: This form of assessment, often called and further referred to in this paper as formative assessment, focuses on the gap between the current knowledge of the learner and the desired goal of the learning. Feedback is key to this form of assessment in order to provide information to the learner to support the learning process. Feedback should be provided during and not after the assessment (Bell \& Cowie, 2001). Assessment is only formative if it results in some action by the teacher and/or learners to enhance learner learning. Learners can use the feedback to monitor their learning while teachers can use the feedback to revise classroom activities and course content.

3. Assessment as Learning: This is part of a cycle of assessment. Learners and teachers set learning goals, share success criteria, and evaluate learning through dialogue and self and peer assessment.

\section{Multiple-Choice Assessment}

Different formats can be used for assessment. The multiple-choice (MC) format is adaptable to all types of subject matter and can be used to assess a wide range of learning outcomes, decision abilities and generic skills (Ng \& Chan, 2012; Riad \& El-Ghareeb, 2008). The conventional or standard MC format provides a statement or questions, with a randomised list of options includ- 
ing one correct answer and several distractors (Scalise \& Gifford, 2006). The scoring is accurate and efficient and learners require much less time to record answers when selecting an MC item (Haladyna, Downing, \& Rodriguez, 2002). Computer systems can be used to efficiently and accurately store and score MC assessments for rapid feedback to learners as well as to save time marking (Nicol, 2007; Olufisoye \& Ola, 2013). The results of assessments can easily be used for item analysis to evaluate knowledge areas that need to be improved. The use of MC tests for assessment in higher education courses has increased over the last decade due to larger learner numbers, reduced resources, and the increasing use of technologies (Nicol, 2007).

The limitations of MC assessment include the enormous amount of time required to develop the assessments, particularly the incorrect options or distractors (Riad \& El-Ghareeb, 2008). In contrast, open-ended questions may be less time consuming to develop, however, more time is required for testing and fewer items can be administered in a fixed amount of time (Haladyna et al., 2002). The use of the MC assessment format is discouraged by many researchers who claim that it promotes memorisation instead of encouraging higher level cognitive processing (Nicol, 2007). Learners do not need to construct a response and, depending on how the questions are constructed, may not need to spend time calculating the answer. The MC format can also be susceptible to guessing (Ng \& Chan, 2012; Riad \& El-Ghareeb, 2008). The feedback provided through MC test questions can also be limited, not allowing personalisation of feedback to learners. Pedagogical principles encouraging effective learning are many times not incorporated in $\mathrm{MC}$ tests (Nicol, 2007).

Alternative methods to the conventional $\mathrm{MC}$ format have been developed to discourage guessing and/or reflect the partial knowledge of learners using the MC format ( $\mathrm{Ng} \& \mathrm{Chan}, 2012)$. The liberal multiple-choice test method allows the selection of more than one answer if there is uncertainty. Elimination testing requires the selection of answers that are believed to be wrong. The confidence marking method requires candidates to assign a confidence level to their best choice answer to a question. The probability testing method requires candidates to allocate 100 points among all given alternatives to reflect their perceived probability of being correct. Complete and partial ordering methods are used to rank the possibility of correctness of alternatives.

Despite the limitations, the MC assessment format is the most versatile type of assessment format (Riad \& El-Ghareeb, 2008). Nicol (2007) outlines how the MC format can be used to support learner self-regulation based on seven principles of good feedback and practice, defined in detail in Nicol and Macfarlane-Dick (2006).

\section{Assessment for Learning: Feedback Principles}

Nicol and Macfarlane-Dick (2006) identified seven principles of good feedback that would support the development of learner self-regulation. The first principle underpins the others: learners must have a reasonable understanding of what is required in assessment tasks in order to selfregulate their own learning. Self-regulation is facilitated by the active construction of knowledge through group interaction, peer feedback, and discussion. Motivation and belief are required for self-regulation as learners need to know that their efforts will produce results.

MC tests can be used to support self-regulation based on the seven feedback principles (Nicol \& Macfarlane-Dick, 2006). The seven principles and their mapping to MC tests as recommended by Nicol (2007, p. 56) are:

- Principle 1: Clarifying goals, criteria and standards. Indicate criteria and standards, as well as allowing learners to construct the tests themselves, thus becoming actively engaged in the criteria for the tests. 
- Principle 2: Self-assessment and reflection. Access to subject resources during the test allows learners to self-assess and self-correct during a testing session. The quality of the questions is also important. Learners should be encouraged to think about and work out answers, not just provide a missing word. In addition, learners could be required to provide a confidence rating. This encourages learners to reflect on the thinking behind their answers.

- Principle 3: Deliver high-quality feedback. Providing alternative feedback to the teacherprepared solution, such as links to classroom activities or other related resources.

- Principle 4: Encourage dialogue around learning. Peer dialogue is an important way of scaffolding learning but MC tests are usually only administered as an individual activity. The feedback and learning power of MC tests can be increased by having learners work in small groups to construct tests or discuss possible answers during a test.

- Principle 5: Positive motivational beliefs and self-esteem. Learners are given repeated opportunities to take MC tests during a course. This has been shown to be highly motivating and the motivation can be enhanced if linked to summative tests of a similar format.

- Principle 6: Closing the gap. Learners can repeatedly take a MC test and check the answers until they achieve satisfactory performance. This allows learners to close the gap between current and desired test performance. Learners should be provided with an indication of what could be considered satisfactory.

- Principle 7: Feedback shaping teaching. MC tests could be presented to learners in preparation for a class or linked to homework assignments. The teacher can use the results to identify areas of learning difficulty and decide where to focus the teaching effort in the class or using future online tasks. MC tests thus do not have to be used just as a means of formative assessment.

\section{Assessment in MathWars}

MathWars is a Mxit application providing mathematics and science content support and assessment to registered Mxit users. Mxit is a South African mobile instant messaging platform enabling real-time text-based chatting between users at a much cheaper rate than the cost of sending an SMS (Ford \& Botha, 2010). The main purpose of the MathWars application is to support aims of the Govan Mbeki Mathematics Development Unit (GMMDU) based in the Science faculty of the Nelson Mandela Metropolitan University (NMMU) in South Africa. The GMMDU focuses on mathematics and science development amongst educators and learners in the Eastern Cape Province, specifically focusing on assisting learners and educators in rural communities disadvantaged by the lack of access to proper learning resources. The learning content provided by the MathWars application is supplied by the GMMDU. The MathWars application is only one component of the work done by the GMMDU to provide learning resources and scaffolded support to learners and educators. Curriculum aligned content video lessons and workbooks form the basis of a techno-blended teaching and learning model that is used by the unit for development, including providing learners participating in the GMMDU development programmes with tablets. The MathWars application complements the GMMDU programme by allowing all users with a mobile device access to the system to assess their knowledge of the subject learning content. 


\section{Functionality}

The MathWars application consists of different components. One component is a level-based quiz. All users start at level 1 and proceed to the next level after completing a minimum number of tests at the level and achieving an average score above a specified score. The mixture of test questions is adapted by including questions from the previous level if the user average is low, and including questions from the next level if the user average is high. The questions were sourced from past national Mathematics Olympiad competition questions and are problem-solving type questions.

The MathWars application also provides support for learners involved in the GMMDU programme by providing access to mathematics and science tests used for summative assessment. After the summative assessment period is completed, the tests are freely available as a learning resource, allowing all users to attempt these tests an unlimited number of times. Learners also have access to past papers and solutions used as the end-of-year formal summative assessment by the South African Department of Basic Education.

Another component of the MathWars application is MathMxit, which is an Olympiad-type mathematics competition with pilot categories (in 2013) for Grade 9 and a Grade 11 level content. The questions are based on the application of mathematics subject knowledge gained at each level. The first round is open to all Grade 9 and Grade 11 learners who wish to participate; however, only participants achieving a minimum score are considered for selection to the second and third rounds. The third round of the MathMxit competition is exclusive and typically consists of highlevel problem-solving type questions.

\section{Implementation of Multiple-Choice Assessment in MathWars}

The MathWars application can be accessed by many users at different times from different locations. Tests are assessed by the MathWars application and immediate feedback is provided to users. The MC assessment method was selected due to the advantages outlined previously. The submission of short answers to questions would require the answer to be verified. Verification would require the spelling of the answer to be correct in order for the MathWars application to mark the answers without user intervention. A phonetic algorithm such as Soundex (Pinto et al., 2012) could be used to match the answer; however, users tend to use a Mxit lingo and it would be difficult to verify answers with multiple words.

The MC assessment format also suits mathematics and science content. Due to the nature of these subjects, the answers may require notation, formulae, or even diagrams. It is easier to present these options to users using the MC format and require them to select the correct answer by responding with a letter.

The MC tests as part of MathWars are intended to be assessment for learning, thus they should encourage self-regulated learning amongst users. The seven principles of feedback and learning were briefly outlined. MathWars implements all of these principles, although Principle 1 and Principle 4 are not explicitly addressed.

MathWars does not support the construction of tests by learners (Principle 1). All assessments are developed by experts in the field of mathematics and science education to ensure the quality of the learning content and that the content is aligned with the subject curriculum as outlined by the Department of Basic Education. The learning outcomes associated with MC tests are outlined in the subject course curriculum (Department of Basic Education, 2011), thus clarifying learning outcome goals.

Questions and solution feedback for the MathWars application are prepared by subject experts. Tests not administered during a summative testing session have no time limit. Except in cases 
where users complete the test in a controlled environment, the tests can be completed by users in their own time with access to external material (Principle 2). The MathWars application is able to determine the time spent answering a question. This should provide an indication whether users spent time determining answers as opposed to guessing. Users are also provided with high-quality feedback (Principle 3) when presented with the solutions to questions. A link to the related electronic resources and/or textbook is provided as well as detailed calculations and explanations where possible.

The current MathWars app has no functionality to support interaction between MathWars users; however, to promote dialogue around learning (Principle 4), users could complete practice tests in self-organised groups. Mxit is a chat application allowing users to switch between apps within Mxit and chat with their friends. Many smartphones would also allow users access to other chat applications without logging out of Mxit. While collaboration is encouraged for self-regulated learning, certain MC tests are used for summative assessment of user progress. Learners participating in the GMMDU programme are required to complete specific assessments during the week following a teaching session. One requirement of the assessment method is thus to reduce the risk of some learners copying the answers of another learner. The integrity and reliability of results during summative assessments, for example, class tests or competition quizzes, also needed to be ensured. The situation of learners collaborating during a formal test session via chat was addressed by randomising the order of the questions as well as the order of the options provided to answer each question. Time restrictions were also placed on summative tests.

Tests available on the MathWars application that are not being used for summative assessment are available for users to retake at any time, thus allowing users to improve their motivation (Principle 5) and test performance (Principle 6) by closing the gap between current and desired results.

Currently, GMMDU administrators are able to evaluate learner performance as well as view results of different topic areas to identify areas of difficulty (Principle 7). The learner performance can also be evaluated per school and district to identify areas of need.

In addition, the MathWars application had to ensure that learners have the opportunity to review answers provided to questions before submitting the test for evaluation and are provided with explanations of solutions to the questions. Providing explanations with solutions ensures that the assessment is not only of learning but also for and as learning. Two different assessment interface methods were implemented and evaluated.

\section{Assessment method 1}

The first MC assessment interface (Method 1) was implemented with the assumption that the user completes the test immediately; that is, not starting the test and returning to remaining questions after some other activities. After the user has selected a test, the system retrieves the questions and randomises the list of questions and options for each question. The user completes each question in the test sequentially as provided by the system (Figure 1). The system presents the question to the user and the user has only the option to submit an answer or to end the quiz. After submitting an answer, the system displays the next question. Once all questions in the quiz have been answered, the user has the option of revisiting any of the questions in the test (Figure 1). If a user wishes to review a question, the question is displayed with the options randomised again. The answer submitted by the user is also displayed. Once the user is satisfied, the test can be submitted. 


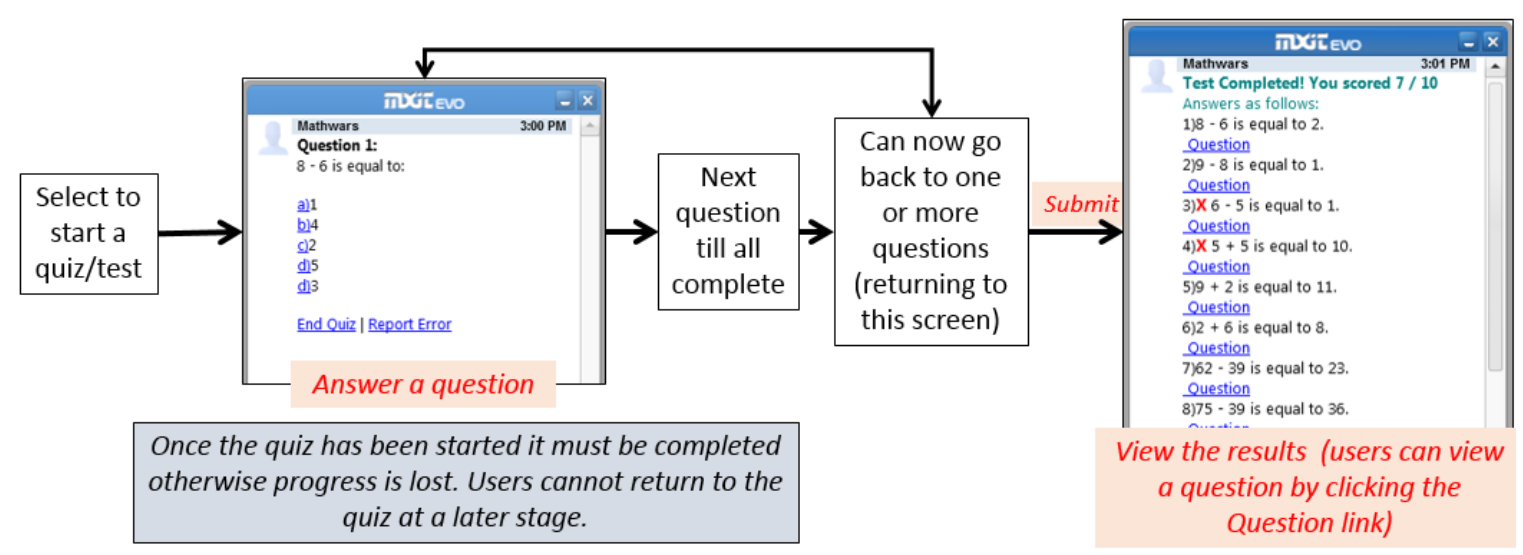

Figure 1. Assessment Method 1

The system then provides the user with a result for the test (Figure 1). For each question in the test, the system indicates if the user was correct and displays a short explanation for the answer. The user is able to view the question and distractors again or view a longer explanation, if available. Once the user has finished viewing the results and solutions, the user is able to retake the test.

If a test is used for summative assessment, the test can be taken a limited number of times. Hints are also displayed to assist users, if a hint is available for a specific question. The user first sees the question without the hint. If the user answers it incorrectly, the question is redisplayed with the hint. However, if the user still answers incorrectly, the test continues with the next question.

This is the first MC assessment interface that was implemented. A limitation of this implementation is that it does not keep a static record of the user's progress. A user session object is used to keep track of the user's progress during the MC test. If the user logs out as a Mxit user or the connection is lost due to unexpected reasons such as running out of airtime or data, or the server becoming unresponsive, the user's progress is lost. Users would have to restart the test. This means that users have to set aside enough time when starting the test to ensure that they can complete all the questions.

\section{Assessment method 2}

The limitation of the first assessment method (Method 1) needed to be addressed by allowing users the opportunity to return to complete a test at another time. This would also ensure that loss of connectivity did not result in users having to restart a test. The second assessment method keeps track of user progress using a database event log. After a user has selected a test the user needs to start the test. The user is then provided with a list of the questions in the test in a random order (Figure 2). The user can select any one of the questions to answer. Every time a question is selected, the options are randomised. The system indicates to the user which questions have already been answered using an asterisk (*) after the question link (Figure 2). If the user logs out and returns to the test, the list of questions is randomly reordered.

Once the user has completed the test, the user can submit the answers for evaluation (Figure 2). Not all the questions need to be answered. The system provides the user with a score for the test. The user can then select any of the questions in the list to view the answer and solution explanation. The test will remain in this state until the user indicates that they no longer wish to view the solutions. The user would then be able to retake the test, if the number of times the test can be taken is unlimited or the limit has not been reached. 


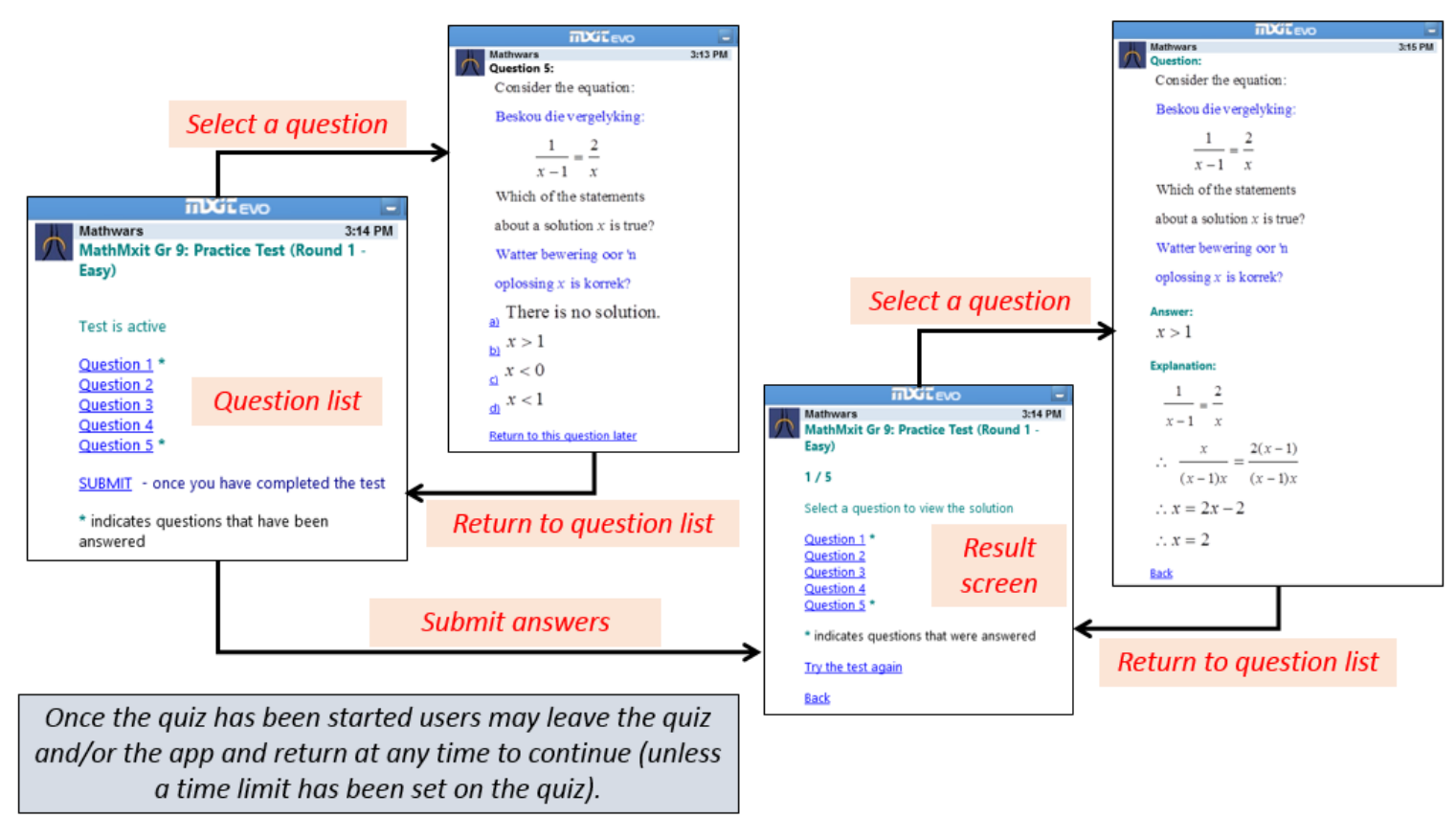

Figure 2. Assessment Method 2

Both MC assessment interfaces have advantages and disadvantages in terms of keeping track of user progress during a test and the validity of the test results. Allowing users the opportunity to return to the test (Method 2) could make it easier for them to collaborate and/or use other resources to determine the answers. The randomisation of questions and answers intends to address this issue. In order to move away from merely theorising regarding which of the two methods is the most appropriate for assessment, both interfaces were evaluated.

\section{Method}

The purpose of the evaluation and this study was to determine the MC interface method that best promotes learning and motivation of users. The evaluation was based on quantitative data from user interaction with tests, test scores obtained, and time spent answering questions and viewing answers. No qualitative feedback was obtained from users during this evaluation. Method 2 was designed and implemented after an expert review to address the shortcomings in terms of loss of connectivity and time constraints that may be associated with Method 1. Method 1 was thus implemented and evaluated first, after which Method 2 was implemented and evaluated.

A Design-based Research (DBR) approach was followed. The functionality provided by the application, including the $\mathrm{MC}$ assessment, underwent a continuous cycle of design-reflection-design by members of the GMMDU who were working with users in the different communities. All user interactions with the system were also logged, providing additional information regarding usage patterns that helped inform design decisions.

In this section, the research questions addressed in this paper are introduced, after which the study design is outlined, including a description of the components and processes used in the preparation and execution of the study. 


\section{Research Questions}

The main aim of the study is to determine whether the assessment interfaces under evaluation support self-regulated learning. The study seeks to answer the following research questions (RQs) in order to evaluate the effectiveness of each of the assessment methods:

1. How did the assessment interfaces compare in terms of the number of users and the number of tests taken?

2. How did the assessment interfaces compare in terms of users retaking tests?

3. What impact did the assessment interfaces have on user performance and progress?

4. How did the assessment interfaces compare in terms of time spent on tests and individual questions?

5. How did the assessment interfaces compare in terms of time spent viewing solutions and explanations?

RQ1 and RQ2 evaluate user motivation to learn while RQ4 aims to determine whether users guessed answers or spent time on the calculations. RQ5 aims to determine whether users used the solutions to improve their knowledge. It is also important to determine whether or not users retaking tests were able to improve their scores (RQ3).

\section{Participants}

MathWars is a live Mxit application that can be accessed by any registered Mxit users. Certain of the mathematics and science support and assessments require users to have a special code provided by the GMMDU. All learners participating in the GMMDU development programme as well as learners participating in the provincial Mathematics Olympiad called MathMxit (hosted on MathWars) have access to special codes, approximately 1500 users in total. The learners are in Grades 9-12, from different urban and rural areas in the Eastern Cape Province, South Africa. Only the interactions of users who have consented to participate in the study are logged for evaluation.

\section{Materials}

All participants in the study have access to the MathWars application using their own mobile devices (or mobile devices they have sourced access to). The participants need to have the Mxit application installed on the mobile device and need to be a registered Mxit user.

No questionnaires were used to collect data in the study. When using the MathWars application for the first time, users who are learners are asked to provide details regarding their age, current grade of schooling, home language, schooling language, and location of the school. Data used for the study was logged automatically by the MathWars application.

\section{Procedure}

The interfaces were evaluated using the tests provided for self-regulated study and assessment. Users had unlimited access to the tests, and this allowed the evaluation of learners' motivation to continue learning and improve scores to be obtained. The tests included mathematics and science tests assessing content in learning outcomes from Grade 10 to Grade 12. Three practice MathMxit competition tests were also available for learners to familiarise themselves with the question format in the competition. 
Summative tests were not used in the evaluation of the interfaces. The only tests of this type presented to users during the time of the study were three MathMxit tests as part of a pilot competition project. Participation was restricted to Grade 9 and Grade 11 learners and only top achieving learners progressed to subsequent rounds.

The time periods used for evaluation were influenced by the research ethics approval process and the fact that MathWars is a live system used to meet the objectives of the GMMDU programme. Method 1 was evaluated for just over seven weeks. The first and second rounds of the MathMxit competition occurred during this period. Method 2 was evaluated after the first interface was evaluated and was included the third round of the MathMxit competition. Fewer learners progressed to the third round of the competition.

MathWars has an event logging system in place to record usage data of consenting users as they interact with the system. This includes navigation from menus to different components of the system. The interaction with tests on the system is also logged in detail, including the time tests were started and submitted, the time a particular question was viewed, the duration for which the question was viewed, and the answer submitted and whether or not it was correct. The system also logs data related to the viewing of solutions, namely which questions were viewed and for how long. The number of times a particular test is attempted, the difficulty of certain questions, and the user average score for a particular test and overall for tests can be determined from the data that is logged. User surveys were not used as a data collection instrument as the majority of the users were minors. The use of questionnaire instruments would have required parental and/or gatekeeper consent which was not possible with the use of Mxit as a freely accessible mobile platform. The user identity cannot be determined from the data, only usage information as described above.

\section{Data Analysis}

The data logged by the MathWars application during the evaluation of the different methods was aggregated using a custom log analyser program. First, data for Method 1 and seven weeks of use of Method 2 were analysed. It was noted that the number of users in the Method 2 data sample was much lower than that of the Method 1 data sample. An additional analysis of Method $2 \log$ data was thus included, where the data collection period is extended resulting in a data analysis period of approximately 15 weeks. The shorter evaluation of Method 2 will further be referred to as Method 27 and the longer evaluation as Method $2{ }_{15}$.

The analysis aggregates user test performance data and provides statistics to describe different performance metrics. The analysis can be used to evaluate the performance of users based on the number of times tests have been attempted. The data metrics evaluated include score and the time spent on a question and/or test. For each the mean, count and standard deviation are calculated.

Independent sample t-tests of unequal sample size and unequal variance are used to evaluate the significance of the difference between the means of the two samples, that is, assessment Method 1 and Method 2, in relation to the Research Questions (RQs) proposed. Two-tailed tests with $\alpha=$ 0.05 are used. Hypotheses are proposed as follows:

$\mathrm{H}_{0}$ : There is no difference between the means of the two methods: $\mathrm{M}_{1}-\mathrm{M}_{2}=0$

$H_{1}$ : There is a difference between the means of the two methods: $M_{1}-M_{2} \neq 0$

The results are presented as a combination of descriptive and inferential statistics. Inferential statistics cannot be applied in certain cases where data has been aggregated and raw data values are unavailable. 


\section{Results}

\section{Research Question 1}

Table 1 presents the overall data for the three evaluations. Method 1 has four times more users than Method 27 and three times more users compared to the longer time period evaluation of Method $2_{15}$. There is also a considerable difference in the number of tests started and submitted. Comparing the number of tests started by users that were actually submitted, or completed in the case of Method 1, a slightly higher percentage of tests were completed using Method 1 compared to using Method 2 (both evaluations). For all three evaluations, the number of tests not completed is greater than the number of tests submitted. The difference between the mean daily submission percentage of Method $1(\mathrm{M}=0.31, \mathrm{SD}=0.18)$ compared to both Method $2_{7}(\mathrm{M}=0.22, \mathrm{SD}=0.25)$ and Method $2{ }_{15}(\mathrm{M}=0.24, \mathrm{SD}=0.29)$ is not statistically significant $(t(82)=1.97, p=0.059$ and $t(174)=1.80, p=0.074$, respectively).

\section{Table 1: Comparison of the number of users and tests used} in the evaluation of the different methods.

\begin{tabular}{lcccccc}
\hline & Method 1 & Method 2 & \multicolumn{3}{c}{ Method 2 } & \\
\hline Number of distinct users & 1274 & & 200 & & 279 & \\
Number of tests started & 4114 & & 335 & & 483 & \\
Number of tests submitted & 1376 & $(33 \%)$ & 94 & $(28 \%)$ & 136 & $(28 \%)$ \\
Number of test not completed & 2738 & $(67 \%)$ & 241 & $(72 \%)$ & 347 & $(72 \%)$ \\
\hline
\end{tabular}

The activity of users with regards to tests started and submitted during the evaluation period is indicated in Figure 3. The high test activity around 27 August on the graph coincides with the first round of the MathMxit competition. Although the MathMxit tests were excluded from the evaluation, users were attempting the MathMxit practice tests and mathematics and science subject support tests. There was a significant difference $(t(51)=2.42, p=0.02$ and $t(51)=2.48, p=0.02)$ between the mean daily number of tests started for Method $1(M=79.12, S D=212.60, n=52)$ compared to both Method $2_{7}(\mathrm{M}=6.98, \mathrm{SD}=6.70, \mathrm{n}=48)$ and Method $2_{15}(\mathrm{M}=5.31, \mathrm{SD}=5.41, \mathrm{n}=91)$, respectively.

In Figure 4, the graph shows the number of tests started and submitted every day, excluding the

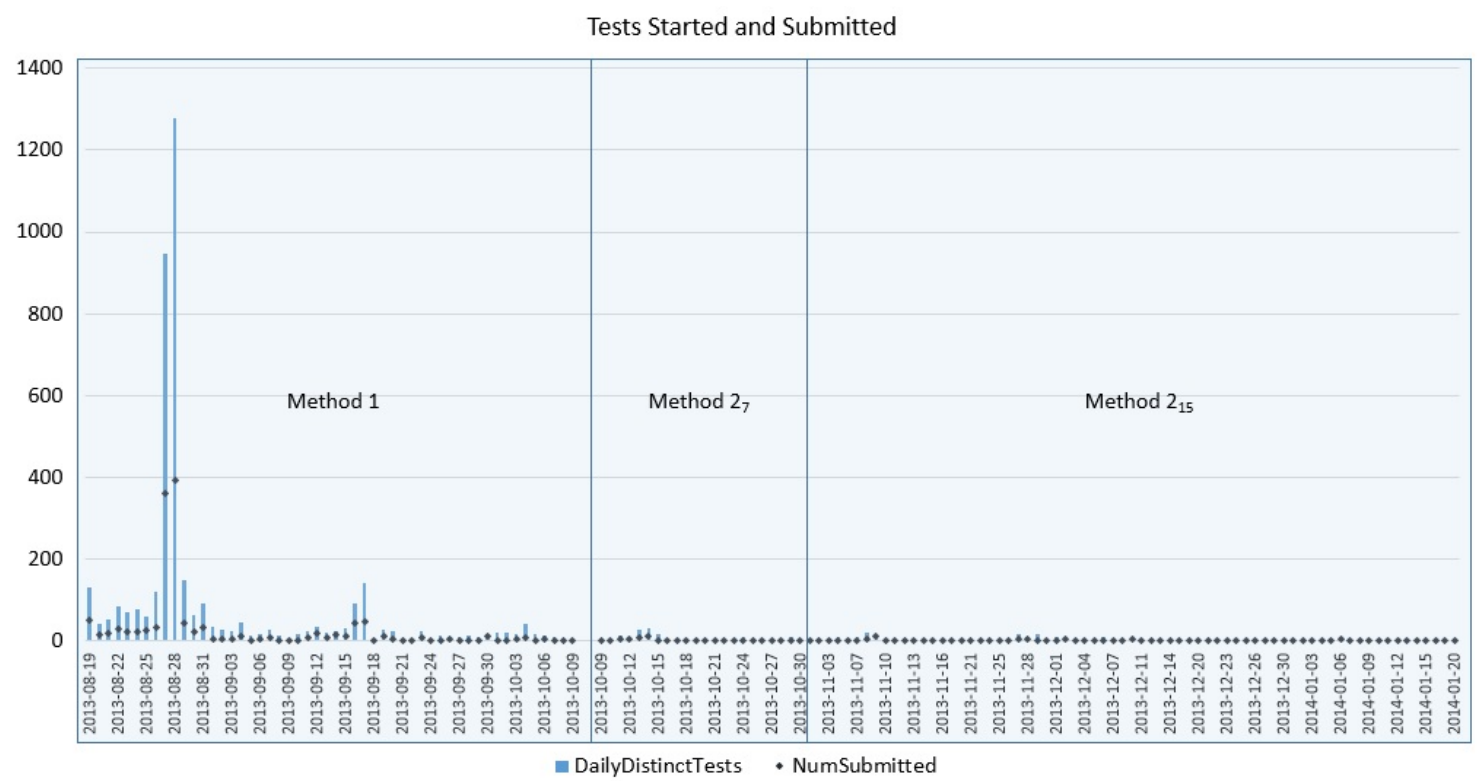

Figure 3. Daily number of tests started and submitted during the evaluation period. 
days around the three rounds of the MathMxit competition. The graph (Figure 4) indicates a decrease in test activity from the beginning of the evaluation period during the evaluation of Method 1. Test activity from 9 October, which is the start of the evaluation for Method 2, shows very low daily test activity, with the exception of certain days when activity increased. The spike on 13 October is leading up to the third round of the MathMxit competition. South African Department of Basic Education national summative assessment examinations for Grade 9, Grade 11 and Grade 12 Mathematics were written during the evaluation period of Method 2. Unfortunately, test activity on the days immediately before these examinations is very low. Analysis of the mean daily number of tests started with the MathMxit competition outliers removed indicates a significant difference $(t(48)=5.64, p<0.01$ and $t(45)=6.04, p<0.01)$ between the mean number of tests started using Method $1(\mathrm{M}=29.18, \mathrm{SD}=26.54, \mathrm{~N}=45)$ compared to Method ${ }_{7}(\mathrm{M}=6.17, \mathrm{SD}=5.37$, $\mathrm{N}=46)$ and Method $2{ }_{15}(\mathrm{M}=4.85, \mathrm{SD}=4.40, \mathrm{~N}=89)$, respectively.

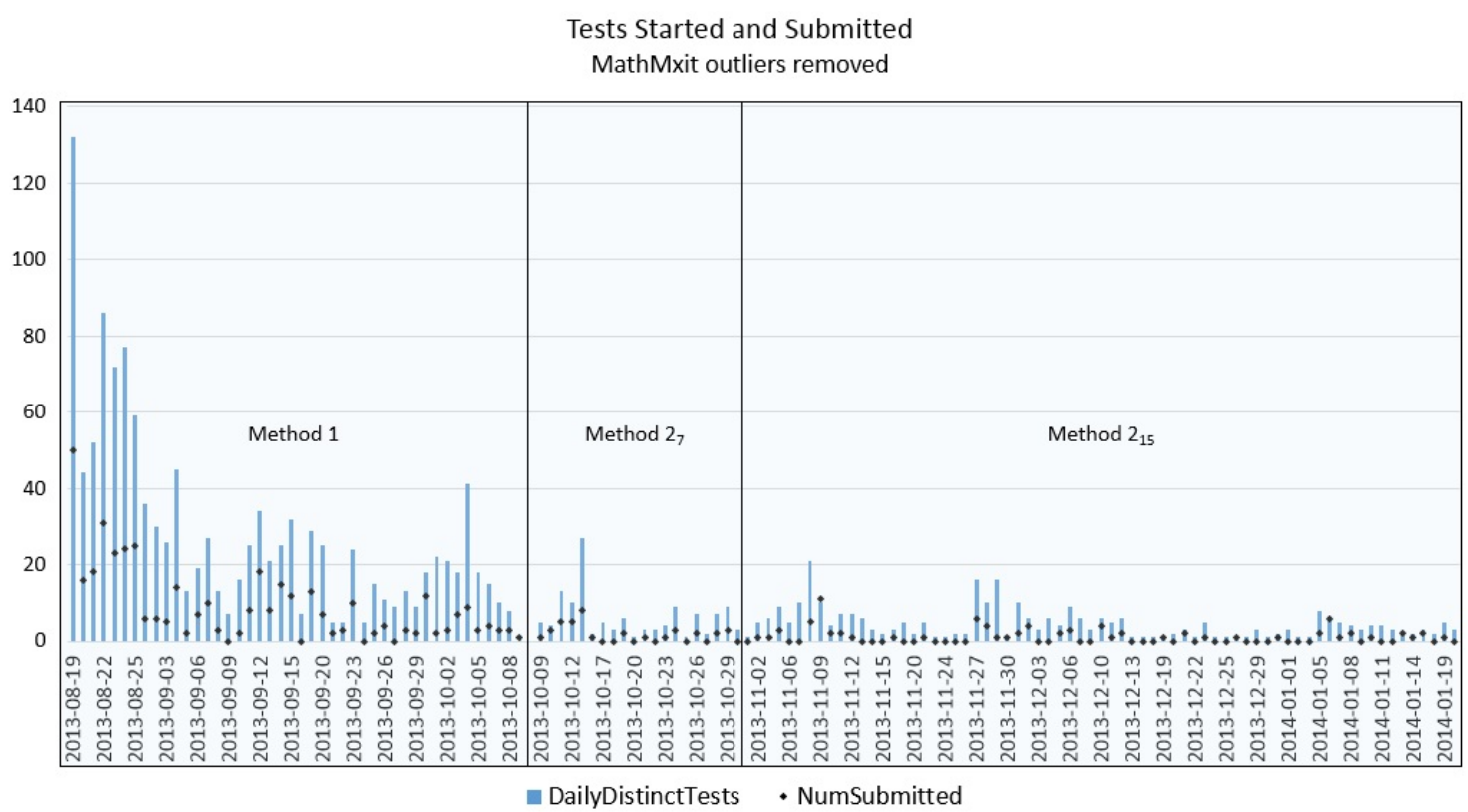

Figure 4. Daily number of tests started and submitted with MathMxit outlier days removed

\section{Research Question 2}

The analysis of tests started and submitted also identified how many times the particular test had been attempted by a particular user. The overall attempt statistics were then aggregated. Table 2 presents the analysis of the attempts per method. The first observation is that Method 1 had tests attempted more than four times, with the highest number of attempts for a test being 14. Method 2 only had tests attempted up to three times. One test in the Method $2_{15}$ evaluation was attempted a fourth time, but not completed.

The results of RQ1 indicate that a greater number of tests were started and submitted using Method 1 , and this may have contributed to the number of attempts exceeding four. Considering, and comparing, therefore, tests that were attempted up to three times, $52 \%$ of the tests completed in Method 1 were a first attempt and $32 \%$ of tests were a second or third attempt. Method 2 evaluations indicate that over $80 \%$ of tests submitted were a first attempt, and less than $20 \%$ were a second or third attempt. Thus, not only were there a greater number of attempts per test for the Method 1 evaluation, but a greater percentage of tests were attempted beyond the first attempt. 
Table 2. Analysis of attempts per method.

\begin{tabular}{|c|c|c|c|c|c|c|c|c|c|}
\hline & Metho & & & Metl & d 27 & & Meth & d $2_{15}$ & \\
\hline $\begin{array}{l}\text { Attempt } \\
\text { No. }\end{array}$ & $\begin{array}{l}N \\
(1495)\end{array}$ & $\begin{array}{l}\text { Mean } \\
\text { score }\end{array}$ & $\begin{array}{l}\text { \% total } \\
\text { tests }\end{array}$ & $\begin{array}{l}N \\
\text { (83) }\end{array}$ & $\begin{array}{l}\text { Mean } \\
\text { score }\end{array}$ & $\begin{array}{l}\text { \% total } \\
\text { tests }\end{array}$ & $\begin{array}{l}N \\
(125)\end{array}$ & $\begin{array}{l}\text { Mean } \\
\text { score }\end{array}$ & $\begin{array}{l}\text { \% total } \\
\text { tests }\end{array}$ \\
\hline 1 & 783 & 38.95 & $52 \%$ & 72 & 36.20 & $87 \%$ & 103 & 34.21 & $82 \%$ \\
\hline 2 & 310 & 52.52 & $21 \%$ & 9 & 48.89 & $11 \%$ & 17 & 48.82 & $14 \%$ \\
\hline 3 & 158 & 57.03 & $11 \%$ & 2 & 60.00 & $2 \%$ & 4 & 65.00 & $3 \%$ \\
\hline 4 & 90 & 59.44 & $6 \%$ & & & & 1 & 0.00 & $1 \%$ \\
\hline 5 & 57 & 57.72 & $4 \%$ & & & & & & \\
\hline 6 & 31 & 67.74 & $2 \%$ & & & & & & \\
\hline 7 & 20 & 77.50 & $1 \%$ & & & & & & \\
\hline 8 & 14 & 75.71 & $1 \%$ & & & & & & \\
\hline 9 & 12 & 77.50 & $1 \%$ & & & & & & \\
\hline 10 & 8 & 67.50 & $1 \%$ & & & & & & \\
\hline 11 & 4 & 85.00 & $0 \%$ & & & & & & \\
\hline 12 & 4 & 90.00 & $0 \%$ & & & & & & \\
\hline 13 & 3 & 86.67 & $0 \%$ & & & & & & \\
\hline 14 & 1 & 100.00 & $0 \%$ & & & & & & \\
\hline
\end{tabular}

\section{Research Question 3}

RQ3 evaluates the impact of the both assessment methods on user performance and progress. In this study, the impact of the methods on user performance is compared by evaluating the distribution of scores obtained for assessments (tests). User progress in this study aims to evaluate whether users, who attempted a specific test multiple times, were able to improve their scores, considering that they were presented with question solutions after completing a test.

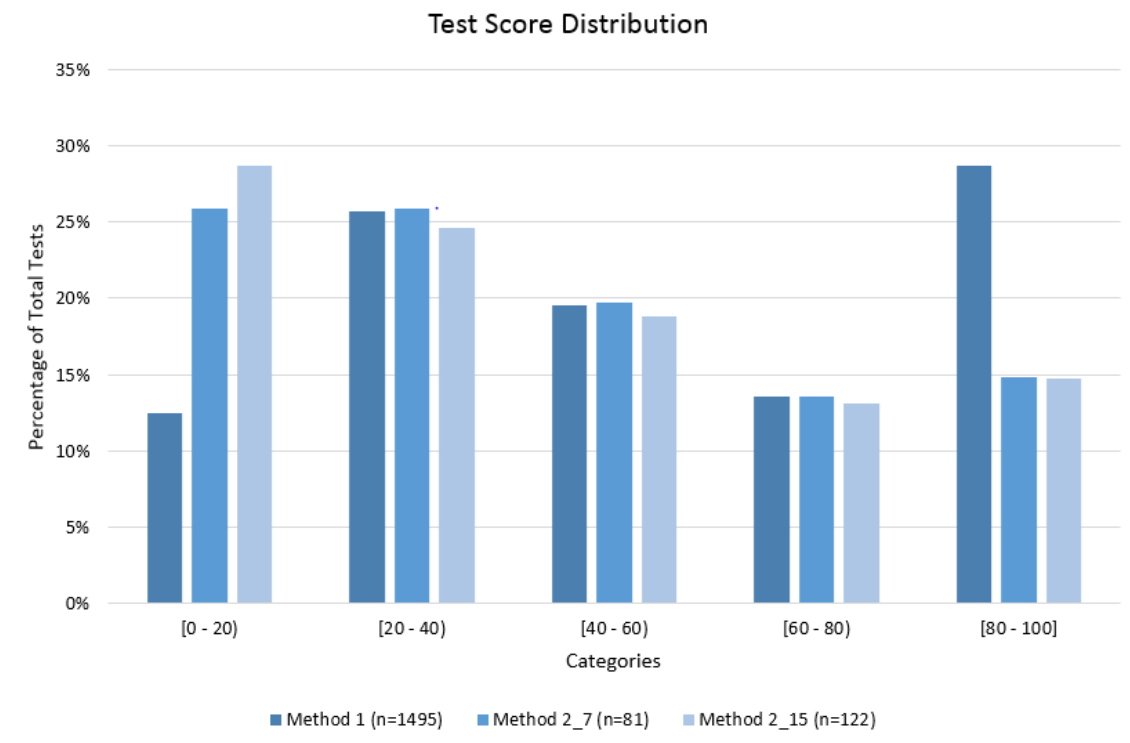

Figure 5. Comparison of test score distribution

Figure 5 presents a distribution of test scores across five score categories. Approximately a third of the tests completed using Method 1 scored between $80 \%$ and $100 \%$. Less than a third of tests in both Method 2 evaluations scored above $60 \%$. Considering the results presented in Table 2, the reason may be that very few Method 2 users attempted tests two or more times. It is also clear 
from the results that the order in which the evaluations were done does not affect the results as it would be expected that users who first completed tests in Method 1 would obtain higher scores using Method 2 after being presented with solutions.

Table 2 indicates the mean test score per attempt for all three assessment methods. The results are similar in that there is an improvement in test score as the number of attempts increases (positive correlation between the mean test score and the number of attempts). Both Method 2 evaluation results show that users no longer attempted tests when the test score of approximately $60 \%$ or more is obtained. Figure 6 presents similar results when analysing the attempts of Method 1.

The bars in the graph (Figure 6), for each particular attempt (x-axis) in Method 1, indicate the mean scores obtained by that group for each attempt up to and including the particular attempt. For example, where users attempted a test twice (label 2 on the x-axis), the average was just below $40 \%$ on the first attempt and approximately $55 \%$ on the second attempt. The last attempt mean score for all attempt groups, except when tests were attempted only once (Attempt 1), was greater than $50 \% ; 60 \%$ in the cases of three and four attempts and at least $70 \%$ in cases of seven or more attempts. Where tests were attempted eight, twelve and fourteen times, users consistently achieve high scores for each attempt but continued to redo the tests. The scores on the first and/or second attempt in these cases was also high (60\% or above). The results identify three cases: users not continuing after the first attempt when the score is low; user starting with low scores but continuing until a user-acceptable score is obtained, which varies from $50 \%$ to $100 \%$, and users trying to consistently achieve high scores with multiple attempts.

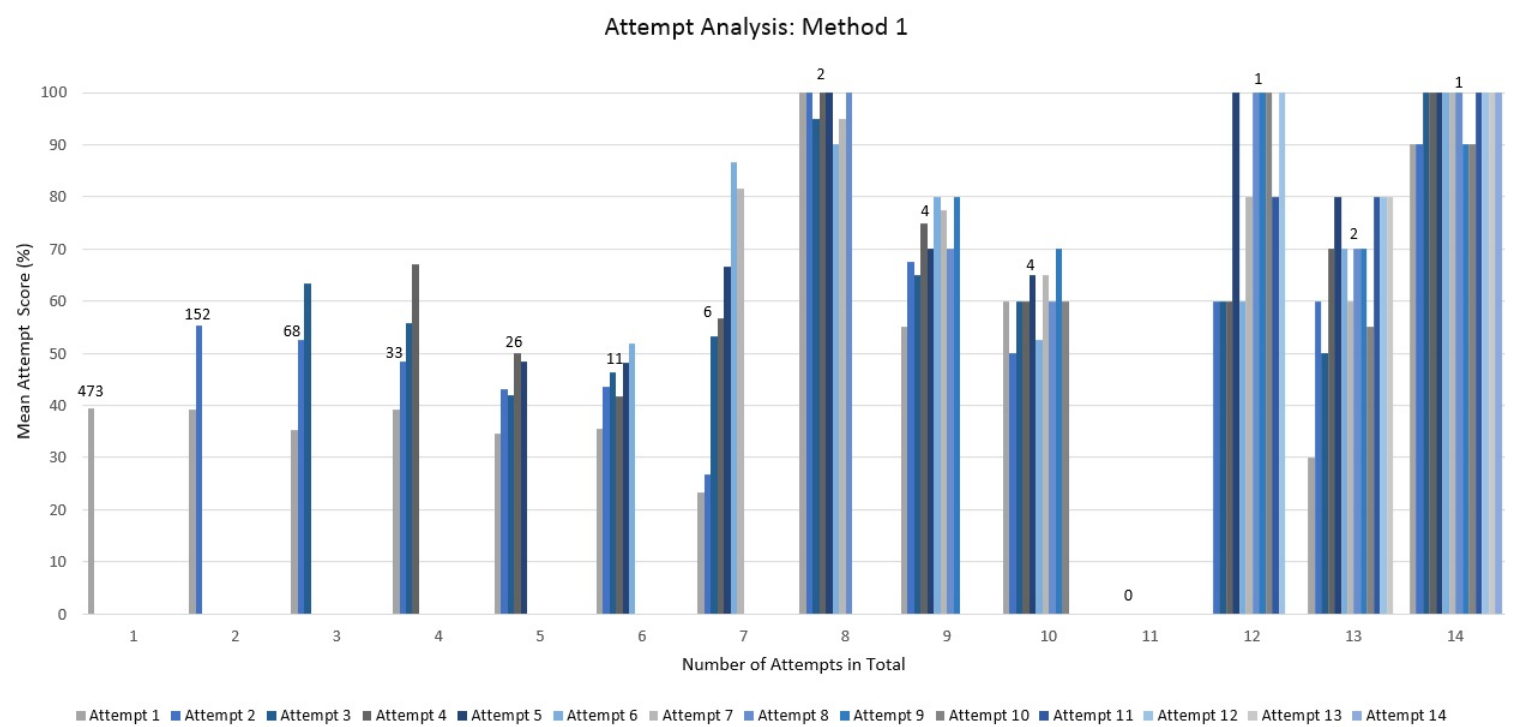

Figure 6. Mean attempt score using assessment Method 1

\section{Research Question 4}

Analysis of the time spent completing tests and answering questions provides an indication of whether users simply select answers or spend time calculating the answer and/or use other resources to determine the answer. The mean time spent on completing tests (Table 3) using Method 2 (both evaluations) was far greater compared to using Method 1. Tests uncompleted for a long period of time may skew the mean value results; however, the median values are also greater for Method 2. 
Table 3. Time spent (minutes) completing tests.

\begin{tabular}{llll} 
& Method 1 & Method 2 & Method 2 15 \\
\hline Mean & 7.55 & 72.17 & 401.22 \\
Median & 7.46 & 26.35 & 98.00 \\
SD & 45.09 & 983.00 & 5151.19 \\
N & 1495 & 81 & 122 \\
\hline
\end{tabular}

Table 4. Time spent (minutes) per question.

\begin{tabular}{llll}
\hline & Method 1 & Method 2 & Method 2 \\
\hline Mean & 1.38 & 1.57 & 1.91 \\
SD & 5.48 & 3.19 & 3.55 \\
N & 388 & 260 & 352 \\
\hline
\end{tabular}

Users spent slightly less time on average viewing questions using Method 1 compared to both evaluations of Method 2 (Table 4). A paired two-samples t-test for a difference in mean values between questions answered in Method $1(\mathrm{M}=1.27,1.44)$ and Method $2{ }_{7}(\mathrm{M}=1.53, \mathrm{SD}=3.25)$ indicated no significant difference between the means $(t(222)=-1.13, p=0.262)$. However, there is a significant difference $(t(265)=-2.96, p=0.003)$ between the means of Method $1(\mathrm{M}=1.20$, $\mathrm{SD}=1.40)$ and Method $2{ }_{15}(\mathrm{M}=1.88, \mathrm{SD}=3.63)$.

\section{Research Question 5}

Method 1 and Method 2 differ in the presentation of solution results to users (see sections on Assessment Method 1 and Method 2). Method 1 displays the solutions for the questions on one screen once all the questions have been completed. Users can then select to view question and distractors again or view a more detailed explanation for the question, if it exists. Only 7\% (91) of users in Method 1 viewed questions and distractors and/or viewed more detailed explanations after completing the test.

Method 2 displays a list of questions after the test is submitted. Users can clear the test without viewing any solutions. Users have to specifically select questions to view the question and solutions, unlike Method 1 that automatically displays the list of solutions to users on completion. Only 12\% (23) of users in Method $2_{7}$ and 13\% (36) of users in Method $2_{15}$ selected to view solutions. All Method 1 users would see the solutions after the test is completed.

\begin{tabular}{llll}
\multicolumn{4}{c}{ Table 5. Time spent (minutes) viewing solutions. } \\
\hline & Method 1 & Method 2 & Method 2 $\mathbf{1 5}_{\mathbf{7}}$ \\
\hline Mean & 1.14 & 0.64 & 0.72 \\
SD & 8.85 & 2.96 & 2.68 \\
N & 1097 & 339 & 492 \\
Total & 1252.12 & 216.83 & 356.67 \\
\hline
\end{tabular}

Table 5 presents the time spent viewing the test solutions displayed after completing a test in Method 1 and the time spent viewing selected questions solutions after submission, using Method 2. Users spent on average just over a minute viewing solutions using Method 1, while spending approximately 40 seconds to view solutions between submitting answers and exiting the test using Method 2.

A comparison of the time spent viewing individual question solutions could not be performed due to the difference in which the two assessment methods present question solutions to users. Analy- 
sis of the time spent viewing solutions using Method 2 (when users viewed solutions) showed that users spent, on average, approximately a minute $(\mathrm{M}=0.94, \mathrm{SD}=1.46, \mathrm{~N}=298)$ viewing question solutions. The analysis discarded data where the questions were viewed for longer than 10 minutes as this was considered user inactivity on the system.

\section{Discussion}

The study evaluates two MC assessment interface methods to determine how each supports the principles for self-regulated learning (Nicol, 2007) and learner performance. Both assessment methods enable users to self-test their understanding (Principle 2) and provide immediate feedback in terms of mark obtained and solutions (Principle 3) once the test is completed. Users are also able to repeatedly attempt tests to allow them to reinforce their knowledge of the subject content and thus increase their motivation (Principle 5).

An important finding from the results of RQ1 is that a very low percentage (approximately 30\%) of tests started by users - for both assessment interfaces - were completed. The mean number of daily tests completed using Method 1 was significantly greater than the Method 2 evaluations. Assessment cannot be effective if it is not actively used in the learning process. The reason for the low submission/completion rate of tests could be as a result of the users not being motivated to continue using the assessment and application, possibly as a result of the principles not being applied properly, or the design of the interface confuses users thus impacting motivation and use. It is important that technology should promote the learning process (Snell \& Snell-Siddle, 2013; Tallent-Runnels et al., 2006). The number of users taking tests may be increased if it formed part of a teacher-centered instructional strategy (Sweat-Guy \& Wishart, 2008) that can promote class attendance, participation, and performance (DePaolo \& Wilkinson, 2014). A self-regulating strategy may cause users to prioritise their use of time towards other educational activities with stricter deadlines and criteria for formal assessment, instead of participating in the assessments in this study for no explicit reason.

Investigating these reasons further, results of RQ2 show that when using assessment Method 1, users attempted tests more times (maximum of 14) compared to users using assessment Method 2 (maximum of 3). A greater percentage of tests were also attempted beyond the first attempt using Method 1 compared to Method 2. A closer look at the performance per test (RQ3) shows that in all evaluations, the user performance improved with subsequent attempts. Method 2 results show that users no longer attempted tests when a score (mean) of $60 \%$ was obtained. Similarly, Method 1 results indicated that, except for the first attempt, users no longer attempted tests if a score of at least $50 \%$ was obtained. Method 1 results further identify three cases. The first case is users that obtain a below average score on the first attempt and do not continue. These users are not motivated to re-attempt the assessments to obtain a higher score. The second case is users that continue until a target score is obtained, which varied between $50 \%$ and $100 \%$. In this case it seems that users continue attempting tests until a satisfactory performance is achieved (Principle 6). This was evident in the evaluations of both Method 1 and Method 2. The third case is users that continue attempting tests to consistently achieve high scores. This encourages positive motivational beliefs and builds self-esteem (Principle 5), evident in the evaluation of Method 1.

A limitation of both assessment interfaces is that no clear goals were made available to users for the assessments (Principle 1), specifically what an acceptable performance for the assessment would be. Focusing learners through feedback on learning and performance goals leads to higher achievement (Nicol \& MacFarlane-Dick, 2006). Specific performance goals would motivate users to re-attempt tests.

The provision of high-quality feedback and solutions (Principle 3) should build user understanding of learning content and give users the confidence to attempt the assessment again to close the 
gap until satisfactory performance is reached (Principle 6). Both assessment methods provide the same solution content developed by subject experts and provide links to related resources (Principle 3). However, due to the interface design, the solutions and feedback are provided differently. All users who completed a test using Method 1 would be presented with the solutions to questions, while only $12 \%$ and $13 \%$ of users selected to view question solutions for Method 27 and Method $2{ }_{15}$, respectively. This may attribute to the lower percentage of users using Method 2 who attempted tests more than once.

The time spent completing the assessment questions is a reflection of whether users think about the answers to the item questions and access other supporting resources (Principle 2). Method 1 presents users with questions in a random order, while Method 2 allows users to select questions to answer. Users can also easily return to questions using Method 2. On average, Method 2 users spent longer on tests and specific questions. The mean amount of time spent on tests and questions indicates that the majority of users in both evaluations did not guess answers but spent time thinking about and/or calculating the correct response.

\section{Conclusions}

The evaluations of two MC assessment methods for a text-based mobile application to support self-regulated learning have been presented. An assessment method can only support the learning process if it is actively used by learners. The sequential presentation of questions to users (Method 1) resulted in a higher completion rate of tests, probably due to the fact that users could not return to the test at a later stage and had to complete the test at that time. However, the more relaxed design of allowing users to select questions and return at a later time (Method 2) seemed to allow users to spend more time working on the questions, even though overall performance was better using Method 1.

An important result and contribution of the study is the insight obtained regarding the presentation of solutions and feedback. Feedback is important in the self-regulation process of learners to refine their knowledge of subject content. Solutions and feedback for assessment should not be optional or user-selected, as in Method 2, but should always be presented and visible, even if only concisely. An indication of performance goals for each assessment, regardless of the interface design used, is also important. Performance goals allow learners to identify their learning goals and be able to close the gap between their current and expected performance, motivating learners to reassess their knowledge.

This study evaluates two different assessment interfaces and provides findings on how even the simplest design differences can impact the user interaction with the system. With the development of learning management systems, allowing not only the viewing of static learning content and formal assessment, but also interaction between learners, more research should be focused on the development of guidelines to support these different learning components. M-learning systems can play a very important role in providing users with access to learning resources and assessments which in turn can increase users' knowledge and their motivation for learning. However, technology should support, not impede, the learning process. The importance and impact of the presentation of the learning content should not be diminished.

\section{Acknowledgements}

Thank you to the FirstRand Chair in Mathematics Education Initiative as the project sponsor and for providing financial support for the postdoctoral research of Melisa Koorsse through the GMMDU. Thank you to Charl van der Merwe (Department of Computing Sciences, NMMU) for support and technical assistance regarding the deployment of the application. 


\section{References}

Andronica, A., Carbonaro, A., Casadei, G., Colazzo, L., Molinari, A., \& Ronchetti, M. (2003). Integrating a multi-agent recommendation system into a mobile learning management system. Proceedings of the Artificial Intelligence in Mobile System 2003 (AIMS 2003), Seattle, USA, October 12, 2003.

Bell, B., \& Cowie, B. (2001). The characteristics of formative assessment in science education. Science Education, 85, 536- 553.

Chu, H-C., Hwang, G-J., \& Tsai, C-C. (2010). A knowledge engineering approach to developing mind tools for context-aware ubiquitous learning. Computers \& Education, 54, 289-297.

DePaolo, C. A., \& Wilkinson, K. (2014). Recurrent online quizzes: Ubiquitous tools for promoting student presence, participation and performance. Interdisciplinary Journal of E-Learning and Learning Objects, 10, 75-91. Retrieved from http://www.ijello.org/Volume10/IJELLOv10p075091DePaolo0900.pdf

Department of Basic Education. (2011). Curriculum and assessment policy statement Grades 10-12: Mathematics.

Earl, L. M. (2003). Assessment as learning: Using classroom assessment to maximize sudent learning. Corwin Press.

Ford, M., \& Botha, A. (2010). A pragmatic framework for integrating ICT into education in South Africa. Proceedings of IST-Africa 2010, Durban, South Africa, May 19-21, 2010.

Gikandi, J., Morrow, D., \& Davis, N. (2011). Online formative assessment in higher education: A review of the literature. Computers \& Education, 57, 2333-2351.

Greyling, J. H., Koorsse, M., Ngundu, T., \& Kyazze, M. (2013). Mobile Instant Messaging (MIM) applications to assist learning in South Africa. Educational Research for Social Change, 2(1).

Haladyna, T. M., Downing, S. M., \& Rodriguez, M. C. (2002). A review of multiple-choice item-writing guidelines for classroom assessment. Applied Measurement in Education, 15(9), 309-333.

Hwang, G.-J., \& Chang, H.-F. (2011). A formative assessment-based mobile learning approach to improving the learning attitudes and achievements of students. Computers \& Education, 56, 1023-1031.

Keble, J. (2012). An investigation into the low pass rate in science and mathematics in selected schools in the northern areas, Port Elizabeth. Masters Dissertation. Nelson Mandela Metropolitan University.

Martin, F., \& Ertzberger, J. (2013). Here and now mobile learning: An experimental study on the user of mobile technology. Computers \& Education, 68, 76-85.

Martin, R., McGill, T. J., \& Sudweeks, F. (2013). Learning anywhere, anytime: Student motivators for mlearning. Journal of Information Technology Education: Research, 12, 51-67. Retrieved from http://www.jite.org/documents/Vol12/JITEv12ResearchP051-067MartinFT51.pdf

Motiwalla, L. (2007). Mobile learning: A framework and evaluation. Computers \& Education, 49, 581596.

Ng, A. W., \& Chan, A. H. (2012). An evaluation of three multiple-choice assessment methods in a human factors engineering course. Journal of the Chinese Institute of Industrial Engineers, 29(7), 466-476.

Nicol, D. (2007). E-assessment by design: Using multiple-choice tests to good effect. Journal of Further and Higher Education, 31, 53-64.

Nicol, D., \& Macfarlane-Dick, D. (2006). Formative assessment and self-regulated learning: A model and seven principles of good feedback practice. Studies in Higher Education, 31(2), 198-218.

Olufisoye, A. C., \& Ola, A. T. (2013). An integrated e-learning examination model using combined MCQ and essay based full blind marking assessment technique. Journal of Automation and Control Engineering, 1(2), 135-139. 
Pinto, D., Vilarinõ, D., Alemán, Y., Gómez, H., Loya, N., \& Jiménez-Salazar, H. (2012). The Soundex phonetic algorithm revisited for SMS text representation. Text, Speech and Dialogue, 7499, 47-55. Springer.

Pintrich, P. R., \& Zusho, A. (2007). Student motivation and self-regulated learning in the college classroom. In R. Perry \& J. Smart (Eds.), The scholarship of teaching and learning in higher education: An evidence-based perspective (pp. 731-810). Netherlands: Springer.

Quinn, C. (2001). Get ready for m-learning. Training \& Development, 20(2), 20-21.

Riad, A., \& El-Ghareeb, H. (2008). A service oriented architecture to integrate mobile assessment in learning management system. Turkish Online Journal of Distance Education, 9(2).

Sadler, D. R. (1998). Formative assessment: Revisiting the territory. Assessment in Education, 5(1), 77-84.

Scalise, K., \& Gifford, B. (2006). Computer-based assessment in e-learning: A framework for constructing "intermediate constraint" questions and tasks for technology platforms. Journal of Technology, Learning and Assessment, 4(6).

Sharples, M., Taylor, J., \& Vavoula, G. (2005). Towards a theory of mobile learning. In MLearn 2005, 1, $1-9$.

Sheppard, D. (2011). Reading with iPads - The difference makes a difference. Education Today, 3, 12-15.

Snell, S., \& Snell-Siddle, C. (2013). Mobile learning: The effects of gender and age on perceptions of the use of mobile tools. In The Second International Conference on Informatics Engineering \& Information Science (ICIEIS2013), 274-281. The Society of Digital Information and Wireless Communication.

Sweat-Guy, R., \& Wishart, C. (2008). A longitudinal analysis of the effects of instructional strategies on student performance. Issues in Informing Science and Information Technology, 5, 149-163. Retrieved from http://proceedings.informingscience.org/InSITE2008/IISITv5p149-163Sweat430.pdf

Tallent-Runnels, M., Thomas, J., Lan, W., Cooper, S., Ahern, T., Shaw, S., \& Liu, X. (2006). Teaching courses online: A review of the research. Review of Educational Research, 76, 93-135.

Tan, T.-H., \& Liu, T.-Y. (2004). The MObile-Based Interactive Learning Environment (MOBILE) and a case study for assisting elementary school English learning. In IEEE International Conference on $\mathrm{Ad}$ vanced Learning Technologies (ICALT'04).

Vavoula, G. N. (2005). D4.4: A Study of mobile learning practices: Internal report of MOBIlearn project. . Retrieved April 1, 2014, from http://www.mobilearn.org/download/results/public_deliverables/MOBIlearn_D4.4_Final.pdf

Virvou, M., \& Alepis, E. (2005). Mobile educational features in authoring tools for personalized tutoring. Computers \& Education, 44, 53-68.

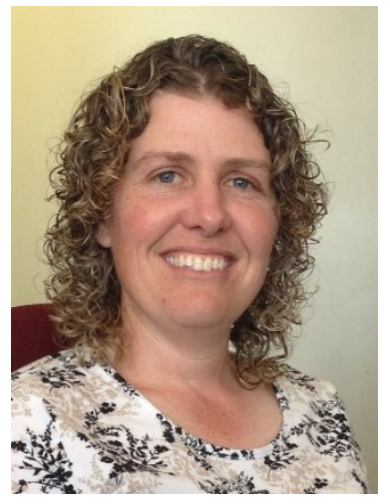

\section{Biographies}

Dr. Melisa Koorsse is a postdoctoral fellow at the Nelson Mandela Metropolitan University, where she obtained her Ph.D. in Computer Science. Her doctoral research was focused on programming tools and software to support IT scholars in South African secondary schools. Her research interests include the use of computers and mobile devices to support education and introductory programming as well as research interests in the field of artificial intelligence and evolutionary computing, specifically related to time-series forecasting. 


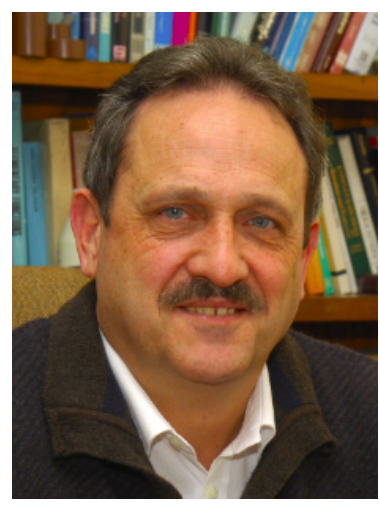

Prof. Werner A. Olivier is a Professor of Mathematics in the Science Faculty at the Nelson Mandela Metropolitan University (NMMU). He also holds a national chair in Mathematics Education sponsored by the FirstRand Foundation. Prof. Olivier earned his undergraduate, master's and Ph.D. in Mathematics from the University of Port Elizabeth (UPE). His research interests include the use of instructional technologies, blended learning, and mathematics education. He has taught mathematics in the NMMU and UPE since 1985.

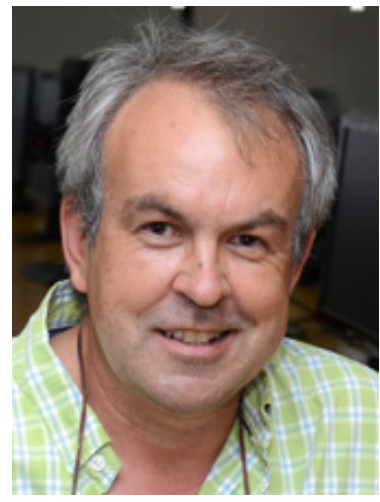

Prof. Jean Greyling is an Associate Professor and Head of Department of the Department of Computing Sciences at the Nelson Mandela Metropolitan University (NMMU). Prof. Greyling earned his undergraduate, masters and Ph.D. in Computer Science from the University of Port Elizabeth (UPE). His research interests include the different aspects related to the education of computing as well as the use of technology for education. He has taught computer science at NMMU and UPE since 1992. 